pollen sterility and fertility behave as a pair of characters in the sweet pea and the velvet bean should in itself be sufficient to give pause to those who would like to regard bad pollen as a proof of hybridity. The theory of mutation equally requires the occurrence of a certain proportion of defective germ cells.

The Hagedoorns, in their recent book on "The Relative Value of the Processes Causing Evolution," also support the idea of the origin of species by crossing, but are obliged to admit that loss mutations must occur, though why they should confine themselves to loss mutations is not clear. It will be necessary to bring some more convincing argument in support of hybridisation as a constructive evolutionary factor before it is likely to receive much serious consideration from biologists.

\section{The Writer of the Article.}

\section{A System of Space-Time Co-ordinates.}

THE common instruments of measurement proposed in theory and employed in practice for the co-ordination of physical events consist of rigid bars and clocks. The limitations of such methods are obvious. The erection of a rigid bar for the direct determination of the distance of the moon from the earth is inconceivable from a practical point of view, while it is a gross absurdity to speak of the measurement of molecular distances by means of rigid bodies. There is only one type of connecting-link across space suitable for co-ordination of events, namely; the lightray. I here define a system of space-time coordinates which involve only one metrical quantity, the vibration period of an atom.

Let there be a vibrating atom at $\mathrm{A}$ emitting lightrays. The time at $\mathrm{A}$ is read from the atom there. Let $\mathbf{P}$ be any other particle, which sends back instantaneously to $\mathrm{A}$ the light-rays arriving from $\mathrm{A}$. Let a ray start from $\mathrm{A}$ at time $t^{\prime}$ and return to $\mathrm{A}$ at time $t^{\prime \prime}$. If an event occurs at $\mathrm{P}$ at the instant of the arrival of the said ray, we shall define two of the coordinates of the event as

$$
\begin{aligned}
\text { distance of event from } A & =x_{1}=\frac{1}{2}\left(t^{\prime \prime}-t^{\prime}\right), \\
\text { time of event } & =x_{4}=\frac{1}{2}\left(t^{\prime \prime}+t^{\prime}\right),
\end{aligned}
$$

the expressions in italics being defined by these statements.

Let $\mathrm{B}$ and $\mathrm{C}$ be two particles such that $x_{1}$ is constant with respect to time for each of them. Let a light-ray be emitted from $B$ and return to $B$ after reflection from $C$. The departure from $B$ and return to $B$ of this ray are two events at $B$, and we have already defined the time of events occurring at $\mathrm{B}$. Let the ray leave $\mathrm{B}$ at time $x_{4}^{\prime}$ and return to $\mathrm{B}$ at time $x^{\prime \prime}{ }_{4}$. Let $\mathrm{C}$ be so situated that $\left(x^{\prime \prime}{ }_{4}-x^{\prime}\right)$ is constant for all successive rays.

$\mathrm{A}, \mathrm{B}$, and $\mathrm{C}$ constitute the frame of co-ordinates. For sake of example, we may observe that three of the corners of a rigid rectangular block at rest in a terrestrial laboratory satisfy the conditions imposed on $\mathrm{A}, \mathrm{B}$, and $\mathrm{C}$, so far as our experimental accuracy can ascertain; whether they would continue to do so if the block was rapidly revolved about an axis is a matter for experiment to decide.

We have now three particles, $\mathrm{A}, \mathrm{B}$, and $\mathrm{C}$, and from our definitions we can write down the time of an event occurring at any of the three. Let any event $\mathrm{P}$ occur. Let it coincide with the arrival of a lightrav from $\mathrm{A}$ which left $\mathrm{A}$ at $t_{\mathrm{A}}^{\prime}$ and returns to $\mathrm{A}$ at $t^{\prime \prime}{ }_{\mathrm{A}}$ and with the arrival of a rav from $B$ which left $B$ a $t^{\prime}{ }_{B}$ and returns to $\mathrm{B}$ at $t^{\prime \prime}{ }_{B}$, and also with the arrival o a ray from $C$ which left $C$ at $t_{C}^{\prime}$ and returns to $C$ at $t^{\prime \prime}$ c. We define the four co-ordinates of the event $\mathrm{P}$ by the equations :-

$$
\begin{aligned}
& x_{1}=\frac{1}{2}\left(t^{\prime \prime}{ }^{\prime}-t^{\prime}{ }\right) \\
& x_{2}=\frac{1}{2}\left(t^{\prime \prime}{ }_{\mathrm{B}}-t^{\prime}\right) \\
& x_{3}=\frac{1}{2}\left(t^{\prime \prime}{ }_{\mathrm{C}}-t^{\prime} \mathrm{C}\right) \\
& x_{4}=\frac{1}{2}\left(t^{\prime \prime}{ }_{\mathrm{A}}+t^{\prime}{ }_{\mathrm{A}}\right) .
\end{aligned}
$$

It is to be observed that this co-ordinate system, although from the method of definition applicable to the most general gravitational fields, will, in the absence of such fields, give the same values for the co-ordinates of an event as those obtained by rigid body measurements from three points of a rigid body and by a system of clocks.

Department of Mathematics, University of Toronto, Toronto, Canada, September 16.

\section{Aeroplane Photography for Archæology.}

Photographs from an aeroplane taken on a clear afternoon a little before sunset would give good records of ancient British and Roman camps, "castles," villages, rings, pack-tracks, barrows, ditches, and other earthworks, and, as in such photographs taken in Mesopotamia, would probably reveal details that cannot be distinguished by inspection on the ground. Photographs might yield almost as much information as the models in the Pitt Rivers Museum at Farnham, which were made from laborious contour surveying.

There are hundreds of such earthworks on Salisbury Plain, and many of them are, no doubt, related to Stonehenge and to Avebury. The stereoscopic combination of two successive photographs might disclose those parts of the banks and ditches which are nearly obliterated by the village of Avebury. General mode1ling is wanted rather than fine detail. Perhaps such work might be done by learners.

Greystones, reffont, Salisbury, October I2.

$$
\text { A. P. Trotter. }
$$

\section{Cosmic Friction: A Query.}

WRITING with proper deference, I would ask astronomers whether it is not feasible to consider that the solar system may occasionally journey through a region of space occupied by exceedingly diffuse matter? Under such conditions the exceptional appearance of a large meteorite outside the earth's atmosphere might be possible; and some minute shortening of the period of a quickly revolving satellite, like the moon, might show itself by a cumulative advance of position. Contrariwise, if ever (say between 1865 and $187 \mathrm{I}$ ) we passed through regions altogether free from even such evanescent friction, a readily affected comet, like Encke's, might temporarily recover from its usual perturbation.

Oliver Lodge.

\section{Muscular Piezo-electricity?}

THERE is a remarkable similarity between the structure of those organs of electric eels which are generally held to be the source of their "shocks" and the structure of certain artificially grown crystals exhibiting the piezo-electric property. Is it possible that there is a connection between the two, and that these creatures do produce piezo-electricity by the contraction of these organs? I should be interested to know if any of your readers have found any connection between these two phenomena.

E. Wriothesley Russell.

Trinity College, Cambridge, October Io.

No. $27 \mathrm{I} 3$, VOL. IO8] 